This is an electronic reprint of the original article. This reprint may differ from the original in pagination and typographic detail.

Author(s): Palttala, Pauliina; Boano, Camillo; Lund, Ragnhild; Vos, Marita

Title: $\quad$ Communication gaps in disaster management: Perceptions by experts from governmental and non-governmental organizations

Year: $\quad 2012$

Version:

Please cite the original version:

Palttala, P., Boano, C., Lund, R., \& Vos, M. (2012). Communication gaps in disaster management: Perceptions by experts from governmental and non-governmental organizations. Journal of Contingencies and Crisis Management, 20(1), 1-12. https://doi.org/10.1111/j.1468-5973.2011.00656.x

All material supplied via JYX is protected by copyright and other intellectual property rights, and duplication or sale of all or part of any of the repository collections is not permitted, except that material may be duplicated by you for your research use or educational purposes in electronic or print form. You must obtain permission for any other use. Electronic or print copies may not be offered, whether for sale or otherwise to anyone who is not an authorised user. 
Palttala, P., Boano, C., Lund, R., and Vos, M. (2012), Communication gaps in disaster management:

Perceptions by experts from governmental and non-governmental organizations. Journal of

Contingencies and Crisis Management. Vol.20, Issue 1, pp.1-12. DOI: 10.1111/j.1468-5973.2011.00656.x

\title{
Communication Gaps in Disaster Management: Perceptions by Experts from Governmental and Non-Governmental Organizations
}

\author{
Pauliina Palttala, Camillo Boano, Ragnhild Lund and Marita Vos \\ Department of Communication, P.O.Box 35 (A), FI-40014 University of Jyväskylä, Finland \\ E-mail: pauliina.palttala@jyu.fi \\ University College London, DPU, 34 Tavistock Square, London WC1H 9EZ, United Kingdom \\ E-mail: c.boano@ucl.ac.uk
}

\author{
Norwegian University of Science and Technology, Dpt. of Geography, Hogskoleringen 1, 7491 Trondheim, Norway, \\ ragnhild.lund@svt.ntnu.no \\ Department of Communication, P.O.Box 35 (A), FI-40014 University of Jyväskylä, Finland \\ E-mail: marita.vos@jyu.fi
}

The complexity of current disasters creates a challenge for crisis communication. This paper aims at identifying gaps in communication in disaster management experienced in practice in order to facilitate learning from those situations. The research was conducted using a qualitative online open-ended expert questionnaire. It shows that despite the developments in the discipline, communication as an integral part of decision making in disaster management practice needs to be further developed. The paper provides a practical-oriented overview of the communication constraints in complex crisis situations, which has not been provided so far. This research is part of an international project developing performance indicators for a quality measurement system for crisis communication. 
Palttala, P., Boano, C., Lund, R., and Vos, M. (2012), Communication gaps in disaster management: Perceptions by experts from governmental and non-governmental organizations. Journal of

Contingencies and Crisis Management. Vol.20, Issue 1, pp.1-12. DOI: 10.1111/j.1468-5973.2011.00656.x

\section{Introduction}

Crisis communication in the event of major accidents, natural disasters and humanitarian crises is gaining interest in public organizations. This study aims to identify the gaps in communication in disaster management practice, with special focus on the challenges to stakeholder-specific communication in the different phases of a crisis event and on cooperation within the crisis response network. So far management and communication gaps have been studied in specific crisis events. This paper reaches beyond individual crises and takes a more generalized point of view. Similar problems have been encountered in different crisis situations, yet the lessons learned have not led to practical measures. By means of an international questionnaire we collected information on the most prevalent gaps in disaster communication today.

The body of knowledge in the crisis communication literature is relatively rich despite the short history of this academic field, at least in Europe. In the USA crisis communication has long been a core interest in public relations research and practice, particularly in reputation management and image restoration (Falkheimer \& Heide, 2006). However, in the area of disaster management by public organizations, the communicative aspects of crises have been neglected for many years, and crisis communication did not establish itself as an independent research area until after the Chernobyl disaster in 1986 (Nohrstedt and Admassu, 1993). In the aftermath of major catastrophes and natural disasters, e.g. the Tsunami and Hurricane Katrina, growing uncertainty, the increased number and magnitude of crises, and public criticism towards governmental crisis communication have placed the topic firmly on the agenda in public organizations.

Crises usually take organizations and people by surprise, create threatening circumstances and demand a quick response from those responsible (Ulmer, Seeger \& Sellnow, 2007). They necessitate decision making under time pressure. Crises can be divided into intentional crises (such as terrorism, sabotage, workplace violence, and unethical leadership) and unintentional crises (such as natural disasters, disease outbreaks, unforeseeable technical interaction, and product failure) (Ulmer, Seeger \& Sellnow, 2007). In this paper, the term crisis refers to a situation that threatens to harm life and health or the environment, and for which public authorities and non-governmental organizations (NGOs) are the main responders.

Public authorities have a mandate to serve the public interest and to secure the safety of citizens by managing crises effectively. Response organizations, in this context, mean government agencies and rescue organizations which, by law, are obligated to prepare for and manage crises. These organizations attend to disaster management where their own field of authority is concerned. However, crises today are increasingly complicated, and therefore call for the simultaneous involvement of many organizations. The bigger and more severe in its magnitude and negative consequences a crisis is, the greater will be the number of actors, from different societal sectors on the national, regional and local level, occupied in its management. 
Palttala, P., Boano, C., Lund, R., and Vos, M. (2012), Communication gaps in disaster management: Perceptions by experts from governmental and non-governmental organizations. Journal of

Contingencies and Crisis Management. Vol.20, Issue 1, pp.1-12. DOI: 10.1111/j.1468-5973.2011.00656.x

Global risks and crises also require transnational cooperation by public and non-governmental organizations. Currently, NGOs are actively involved worldwide in various large scale natural disasters and humanitarian relief work. Taking these factors into account, it becomes evident that cooperation in a network of response organizations is challenging. This is the case not only for operational tasks but also for communication.

The purpose of this study is to identify gaps in communication supporting disaster management that have been experienced in practice. It is part of a broader research project aimed at developing an audit instrument with indicators to measure and improve crisis communication. The indicators should be based on critical factors found in the literature but should also take into account constraints experienced previously by the users of the instrument. The present study mentions some important insights on crisis communication found in the literature, but focuses on clarifying views on constraints in current crisis communication practice.

\subsection{Basis of crisis communication}

Crisis communication has its origins in public relations and is grounded in strategies to manage and frame public perceptions of an event. It seeks to explain the specific crisis event, to identify likely consequences and outcomes, and hence to provide specific harm-reducing information to affected communities (Reynolds \& Seeger, 2005).

Crisis communication aims to lessen uncertainty, respond to and resolve the situation, and learn from it (Ulmer, Sellnow \& Seeger, 2007). Since crises are unique one-time events, contextual factors need to be taken into account when planning message strategies, as they vary across crisis situations. This is because different crisis threats take different forms, leading to diverse expectations regarding communication (Pauchant \& Mitroff, 1992). Various message strategies from denial to apologia exist, but which strategy is the most useful will depend on the stakeholders' perceptions of the situation and cause (Coombs, 1995; 2004).

The characteristics of present-day crises have also affected the institutions managing them; initially governmental actors, such as the emergency services, police and armed forces, were mainly prepared for disasters and military crises, but nowadays they also have to take a variety of international, political and reputational crises into account (Visuri, 2003). This requires coordination not only at various levels of the hierarchy within the organization but also among the members of the larger response organization network.

Communication needs to be a regular part of crisis management procedures, and decision-making during a crisis situation calls for openness (Visuri, 2003). Breakdowns and contradictions between authorities cause confusion, create additional uncertainty, and hence exacerbate harm (Seeger, 2006). Because of the increased role of the media and insistence of civilians, geographically distant crises also need to be controlled and dealt with irreproachably. Although crises develop unpredictably, they linger and escalate, and a certain linearity in their development can be perceived. Therefore, efficient crisis communication takes into account the 
Palttala, P., Boano, C., Lund, R., and Vos, M. (2012), Communication gaps in disaster management: Perceptions by experts from governmental and non-governmental organizations. Journal of

Contingencies and Crisis Management. Vol.20, Issue 1, pp.1-12. DOI: 10.1111/j.1468-5973.2011.00656.x

developmental stages of a crisis (Reynolds \& Seeger, 2005). Mainly five- and six-stage models have been introduced (e.g. Reynolds \& Seeger, 2005; Moe \& Pathranarakul, 2006), but at their simplest, the stages of a crisis include a pre-crisis or an incubation phase, an acute or crisis phase, which follows a dramatic event, and a post-crisis stage, when questions on cause, responsibility, and preparation for a new crisis are addressed.

A theoretical basis for crisis communication is provided by Reynolds and Seeger (2005), who propose the 'Crisis and Emergency Risk Communication Model' (CERC) in which risk or warning messages and crisis communication are brought together into a more encompassing form. In this process approach it is asserted that communication must begin long before an event erupts, and continue after the immediate threat has subsided. According to Reynolds and Seeger (2005) a single phase can require more than one method of communication when the audience is diverse and its segments are affected in different ways by the crisis in question. Furthermore, this process approach calls for the integration of communication planning both prior to as well as during and after a crisis. In this way, a crisis is regarded as a natural stage in an ongoing evolution (Sellnow, 1993; Weick \& Sutcliffe, 2007; Kersten, 2005).

The above-mentioned Crisis and Emergency Risk Communication Model mentions various stakeholders that should be taken into account. Stakeholders are any group or individual who can affect or is affected by the achievement of the organization's objectives (Freeman, 1984). Although stakeholder theory has been criticised, e.g. for being too static (Key, 1999; Fassin, 2008; Luoma-aho \& Vos, 2010), the basic idea that communication should be adapted according stakeholders' needs is well accepted in the field of communication. Here the concept of stakeholders refers primarily to groups of citizens and communities who are more or less directly involved in the crisis situation, but also to the news media as an intermediary party, and, for purposes of internal communication, other response organizations within the network of actors. Citizens may have various needs for information and expectations towards response organizations. In order for communication to be effective, it is important to monitor stakeholders' perceptions and to understand the way of thinking of the various groups (Vos \& Schoemaker, 2006). This means that throughout the various phases of a crisis the communication needs of citizens should be tracked. Messages are more effective if they match the audience's needs, values, background, culture and experience (Reynolds \& Seeger, 2005). It should be noted that stakeholder groups are not always homogeneous entities but may consists of subgroups with different interests, objectives, agendas and priorities (Fassin, 2008). Thus, a stakeholder approach in crisis communication requires a more detailed analysis of stakeholders' communication needs. 
Palttala, P., Boano, C., Lund, R., and Vos, M. (2012), Communication gaps in disaster management: Perceptions by experts from governmental and non-governmental organizations. Journal of

\subsection{Method}

This study aims at identifying gaps in communication in disaster management experienced in practice. The research question is: what kinds of problems do crisis managers and communication experts encounter when conducting crisis communication in practice? To investigate this, an online questionnaire was conducted in June 2008. It consisted of open-ended questions addressed to experts in governmental organizations (including rescue authorities) and non-governmental organizations (NGOs) on their experiences in disaster management and communication.

The respondents were asked to give their personal opinion as an expert, rather than as a representative of the organization they worked for. Since crises communication strategies depend on situational factors, such as stakeholders' expectations and the developmental stage of the crisis, the respondents were asked to comment on their experiences of communication with stakeholder groups in various phases of a crisis. The questions dealt with the communication constraints experienced with a particular stakeholder group, and challenges of communication related to a specific moment in time.

Three questions concerning communication gaps with different stakeholders were asked: (1) what in your personal experience are the major constraints in communication with the media and the general public; (2) what are the major constraints in communication with affected civilians and communities (e.g. school, church); and (3) what are the major constraints in communication with other organizations that are involved in crisis management and their employees?

The respondents were then asked to specify any phases of a crisis - before, during and after, that pose extra challenges to communication. More specifically, the respondents were asked to identify factors that might hinder communication in either the early or post-crisis phases. Furthermore, the respondents were asked what the most efficient communication system for a disaster would be, and what protocols of communication would be useful in these kinds of situations. Finally, they were asked to mention what should be avoided in crisis communication and what would be their advice for best practices.

The respondents were recruited in various countries within and outside Europe. Via governmental organizations in Europe and international humanitarian response organizations contacts were sought with experience in disaster management and communication. A snowball sampling tactic was used in which contacts were asked to mention experts in other organizations. The invitations, which included the link to the questionnaire, were sent by email. The questionnaire was open for three weeks, during which time one reminder was sent. The total number of invitations was 94, and 40 experts answered the questionnaire. 
Palttala, P., Boano, C., Lund, R., and Vos, M. (2012), Communication gaps in disaster management: Perceptions by experts from governmental and non-governmental organizations. Journal of Contingencies and Crisis Management. Vol.20, Issue 1, pp.1-12. DOI: 10.1111/j.1468-5973.2011.00656.x

Table 1. Respondent background information (more than one answer was possible)

\begin{tabular}{|c|c|c|c|c|c|c|c|}
\hline \multicolumn{2}{|c|}{ Capacities in which involved } & \multicolumn{2}{|l|}{ Institution } & \multicolumn{2}{|l|}{$\begin{array}{l}\text { Geographic } \\
\text { Coverage }\end{array}$} & \multicolumn{2}{|l|}{ Experience } \\
\hline Policy Advisor & 11 & $\begin{array}{l}\text { Academic institution/ } \\
\text { research centre/ } \\
\text { policy institution }\end{array}$ & 15 & Europe & 27 & $\begin{array}{l}\text { Humanitarian } \\
\text { emergencies }\end{array}$ & 22 \\
\hline Communication expert & 10 & $\begin{array}{l}\text { Governmental } \\
\text { organization }\end{array}$ & 16 & Asia & 20 & Natural disasters & 30 \\
\hline $\begin{array}{l}\text { Project/ programme } \\
\text { manager }\end{array}$ & 15 & $\begin{array}{l}\text { Inter-governmental } \\
\text { organization }\end{array}$ & 4 & $\begin{array}{l}\text { South } \\
\text { America }\end{array}$ & 4 & $\begin{array}{l}\text { Technological/ man- } \\
\text { made disasters }\end{array}$ & 16 \\
\hline \multirow[t]{3}{*}{ Academic/ researcher } & \multirow[t]{3}{*}{13} & \multirow{3}{*}{$\begin{array}{l}\text { Non-governmental } \\
\text { organization }\end{array}$} & \multirow[t]{3}{*}{8} & Middle East & 13 & Terrorism & 5 \\
\hline & & & & \multirow[t]{2}{*}{ Africa } & \multirow[t]{2}{*}{17} & $\begin{array}{l}\text { Disaster preparedness } \\
\text { and mitigation }\end{array}$ & 27 \\
\hline & & & & & & Recovery & 18 \\
\hline $\begin{array}{l}\text { Other: } \\
\text { e.g. head of expertise } \\
\text { centre; education and } \\
\text { training; emergency/ } \\
\text { disaster manager; } \\
\text { communication adviser; } \\
\text { mayor in charge of crisis } \\
\text { management }\end{array}$ & 10 & $\begin{array}{l}\text { Other: } \\
\text { United Nations; } \\
\text { independent } \\
\text { consultant; agency }\end{array}$ & 5 & - & - & $\begin{array}{l}\text { Other: } \\
\text { e.g. educational } \\
\text { programmes; } \\
\text { development; } \\
\text { emergency planning; } \\
\text { communication with } \\
\text { press and public; civil } \\
\text { military coordination; } \\
\text { Crowd management }\end{array}$ & 10 \\
\hline
\end{tabular}

According to the theoretical framework explained in section 1.1, the material was analysed from the perspective of various stakeholder groups. The data were organized and analysed, firstly, according to each stakeholder group (citizens, the media, and other response organizations) and the phases of a crisis (before, during and after), separately. After that a deeper content analysis of the answers was conducted and the data were reorganized according to emerging themes by the stakeholder group. Below, for each stakeholder group, the main themes that emerged in the answers are reported along with the phases (before, during or after a crisis) to which the respondents refer.

\section{Results}

According to the findings, response organizations prefer to follow the general protocols of communication set up for normal situations also in the event of a crisis. For public authorities the golden rule of communication in a normal situation is that the information provided should be open and available. In crisis situations, however, this is challenging because of the need for rapid information exchange. Authorities are obligated to give information as quickly as possible, but 
Palttala, P., Boano, C., Lund, R., and Vos, M. (2012), Communication gaps in disaster management: Perceptions by experts from governmental and non-governmental organizations. Journal of

Contingencies and Crisis Management. Vol.20, Issue 1, pp.1-12. DOI: 10.1111/j.1468-5973.2011.00656.x

not at the expense of accuracy and liability. Also, problems occur when actors from different organizational cultures and structures, who thus have their own ways of handling a crisis, need to cooperate. In communications with citizens, a lack of accountability was reported in situations where authorities use intermediaries (partners or translators in international crises) instead of communicating directly with the public. Open communication implies that dilemmas are shared and mistakes apologized for. Communication difficulties after crises included accusations that the authorities were slow, inaccurate or inconsistent in informing the public.

Below, the results of the online questionnaire are presented. Firstly, the comments that referred to communication gaps in the response network are reported. Secondly, the constraints in communication via the media are discussed, and thirdly the challenges in communicating directly with citizens.

\subsection{Communication constraints within the response organization network}

Before a crisis occurs, it is important to identify possible partners and agree on how things are to be divided between the network actors. In well-established relationships the parties have good knowledge of each other's working methods and competences (Palm \& Ramsell, 2007). Mutual agreements along with adequate capabilities serve as a good basis for preparedness. The following gaps in network communication were identified based on the results of the online open-ended questionnaire.

\section{The role of communication}

Communication is not necessarily an integral part of disaster management, and thus the role of communication can be understood very differently. In some cases communication was referred to as channels or means of communication, whereas in others it was understood as a system incorporating various communication functions, such as monitoring, dissemination of information, coordination of tasks, evaluation, and external communication with various publics. Differences in definition should be acknowledged and discussed in the disaster management sector.

Next to the definition of crisis communication its purpose is also considered unclear, as the goals of communication may conflict. In civil crises such as natural disasters the main goal is to rescue people and reduce harm, but there are other agendas as well. One communication goal might be, for instance, to limit reputational damage. Public organizations mostly prioritise reestablishing the public order (Seeger 2006). Also, competition about resources, power, priorities and visibility between response organizations was noted.

"Every organization wants to be in the picture, show their insignias and therefore act only in their own interest. Sometimes they do not see where their capacity is most needed and tend to forget prior agreed behaviour." 
Palttala, P., Boano, C., Lund, R., and Vos, M. (2012), Communication gaps in disaster management: Perceptions by experts from governmental and non-governmental organizations. Journal of Contingencies and Crisis Management. Vol.20, Issue 1, pp.1-12. DOI: 10.1111/j.1468-5973.2011.00656.x

[Project/programme manager of a governmental organization with experience in natural disasters, technological/man-made disasters, and disaster preparedness and mitigation in Europe]

\section{The information flow within the network}

Especially during a crisis, gaps in the information flow within the network exist. As a consequence, decision-making and cooperation are hindered. The reasons for communication breakdowns can be either technical, structural, or be based on differences in organizational cultures. Technical barriers can be overcome by developing and combining communication channels that are versatile and case-specific. The respondents mentioned that clear structures enable efficient coordination, and that authorities usually follow preparedness plans which define responsibilities and division of labour. However, standard operating procedures (SOPs) defining crisis communication on the network level are often lacking and organizations do not share information with each other in a consistent manner based on the same principles. Incident command systems are promoted to help coordination, including integrated communications (Lutz \& Lindell, 2008). The respondents mentioned, however, that in practice information often is not timely, or at other times it is not clear who is supposed to send information and who is the primary target of it. In addition, culture and identity are different, which affects the quality of coordination (Ödlund, 2010). Also, competition may hinder cooperation (Wendling, 2010). The respondents mentioned that different communication styles cause misunderstandings and problems. The respondents stressed that inconsistencies in communication by different organizations create uncertainty among citizens, as actors often do not monitor each other's communication activities and coordination is lacking. Each organization has its own way of doing things and its own structure of command and responsibility. It is difficult to change this in favour of coordination with other organizations.

"Problems in interaction with other response organizations are caused because of the different mandates of organizations depending on how they are financed, as well as their connections to political levels and their defined task(s)."

[Project/programme manager specialized in education and training with experience in humanitarian emergencies, disaster preparedness and mitigation and civil military coordination in Europe]

"During a crisis the different work culture causes problems, e.g. some actors are not used to take fast decisions whereas others are."

[Anonym 2, two respondents did not offer background information]

The respondents stated that time pressure is the main reason behind information gaps. In an uncertain and rapidly changing situation it is quite a challenge for the actors to form and maintain an up-to-date, accurate and complete picture of the whole situation. Keeping up with the course of events requires efficient coordination systems of communication as well as technical capabilities. The parties involved must inform others of their current status and plans 
Palttala, P., Boano, C., Lund, R., and Vos, M. (2012), Communication gaps in disaster management: Perceptions by experts from governmental and non-governmental organizations. Journal of

Contingencies and Crisis Management. Vol.20, Issue 1, pp.1-12. DOI: 10.1111/j.1468-5973.2011.00656.x

concerning their response activities and communication. This would include coordination of messages and press conferences, for instance. Coordination should be efficient; unstructured and time-consuming coordination meetings were criticized by the respondents.

"In my opinion the most effective communication system in an emergency setting is such that coordinates all resources and personnel being used to liquidate the disaster on the one hand - and keeps key people in all agencies informed of the latest developments." [Communication expert and academic researcher of an academic institution/research centre/policy institution with experience in humanitarian emergencies, natural disasters, technological/man-made disasters, terrorism and disaster preparedness and mitigation in Europe]

On some occasions, the parties might be unwilling to share information for various reasons. Trust across the response organization network was seen as crucial and a lack of transparency as a problem. During a crisis it is important to practise an honest and transparent exchange of information between the response organizations involved. However, the respondents reported collisions between actors, as some organizations are easier to work with than others. Problems have occurred, especially between national and international actors, and between military and civil responders. Having a good reputation was seen as a factor improving network communication between the partners. Organizations with a good reputation are considered trustworthy, and other actors are willing to share information with these. The respondents suspected that some organizations consider inter-organizational coordination, where the level of experience differs substantially, a waste of time. Others see coordination as a security risk for their own agency. Due to challenges and scepticism in inter-organizational relations, it is essential to have inclusive and regular coordination that would facilitate accommodating and constructive interaction by responders as rapidly and for as long as possible. Some respondents felt that organizations are not truly interested in communication, and that communication skills are not sufficiently prioritized.

"It is often the case that people in organizations, in fact, do not communicate effectively during a crisis. Often orgs have their own ways of doing things and cultures, and it becomes a problem when they need to cooperate during a crisis. At times an org may not be willing to take onboard information that conflicts with their world view."

[Communication expert and academic researcher of an academic institution/research centre/policy institution with experience in humanitarian emergencies, natural disasters, technological/man-made disasters, terrorism and disaster preparedness and mitigation in Europe]

To conclude, the respondents stated that more uniform decision-making, coordination structures and execution of policies are needed in order to conduct efficient communication. Each organization has its own way of doing things, and changing these in favour of greater integration is a challenge, since cultures develop slowly. Also, it must be clear which level, operational or strategic, predominates in decision-making. In other words it must be planned how 
Palttala, P., Boano, C., Lund, R., and Vos, M. (2012), Communication gaps in disaster management: Perceptions by experts from governmental and non-governmental organizations. Journal of

Contingencies and Crisis Management. Vol.20, Issue 1, pp.1-12. DOI: 10.1111/j.1468-5973.2011.00656.x

communication 'upscaling' from the local to the regional and national level is done. Hierarchical organizational structures adapt poorly in highly uncertain situations. This makes structural preparedness even more important. Decision-making processes during crisis situations should be as open as possible, as fluent information sharing in the network facilitates cooperation.

\section{Evaluation and learning from crises}

Finally, evaluation and learning from crises is not considered good enough. The respondents stressed that after a crisis, organizations should honestly and effectively evaluate what happened and make the changes necessary to increase resilience in future crisis events. A problem in achieving this objective, however, might be that response organizations define the closure of a crisis differently. Furthermore, it is not customary to share experiences within the network after a crisis. Experience and preparedness are linked and the level of tacit knowledge among the actors varies.

Furthermore, the respondents called for the better documentation and dissemination of lessons learned. Currently, organizations do self-evaluations of their performance, but assessments are not discussed together and consequently valuable information is left partially unused. Lessons learned from recent disasters should be taken into consideration and added to a body of 'disaster knowledge'. Careful documentation also enables more accurate assessment and evaluation. In making assessments the following elements were reported to be used: qualitative reports, response time, number of persons rescued and casualties, content analysis of media reports, comparisons of activities according to planning documents, checklists, goals, and values, long-term follow-up evaluations some years after the incident, and lessons-learned meetings and reconstructions based on logs.

"Definitely one challenge is to honestly and effectively evaluate what happened and to make the necessary changes to increase resilience and then to publish those changes." [Communication expert and academic researcher of an academic institution/research centre/policy institution with experience in humanitarian emergencies, natural disasters, technological/man-made disasters, terrorism and disaster preparedness and mitigation in Europe]

\subsection{Communication constraints with the media}

The media are an important intermediary target group and partner for public organizations and NGOs when it comes to communication in crisis situations, as civilians will turn to the media to find out more about a current crisis. Past crises have proven, however, that cooperation between journalists and organizations' spokespersons has been unsatisfactory. Nowadays news dissemination is global and news travels fast. In the following, the reasons reported for gaps in communication with and via the media are presented. 
Palttala, P., Boano, C., Lund, R., and Vos, M. (2012), Communication gaps in disaster management: Perceptions by experts from governmental and non-governmental organizations. Journal of

Contingencies and Crisis Management. Vol.20, Issue 1, pp.1-12. DOI: 10.1111/j.1468-5973.2011.00656.x

\section{Relationships and expectations}

The way of working with the media can be further developed, as building relationships with leading news media supports cooperation in times of crisis. One of the biggest challenges in crisis situations, mentioned by the respondents, is the struggle against time. Authorities are expected to speak about confirmed facts and not to speculate. In reality, making checks on information among the various agents and through the organizational hierarchy is slow, according to the respondents. The media, on the other hand, are often too eager to sit back and wait. News is published as quickly as possible. Past crises have shown that although authorities clearly acknowledge the need for rapid information sharing, they are still too slow compared to the media, and especially the online media. By the time the organization has its information ready, it has often already been published, based on other, and perhaps less reliable, sources. "I would think the challenge of working together with multiple actors and the media is to respond in a way that explains or furthers your version of the story. The main problem in many cases is to stay trustworthy, and to stay the primary source. That is very important if you want to stay ahead of the development. It is therefore important not only to react, but more to set the agenda, be the leading voice in the public."

[Previous communication adviser in a governmental organization with experience in natural disasters in Europe]

"In disasters the basis of communication is the same as in normal situations, but we must try to satisfy the increased demand by giving out information as soon as possible, without sacrificing accuracy and reliability."

[Communication expert of a governmental organization with experiences in natural disasters and crime in Europe]

The respondents mentioned that the struggle to reduce time lags leads to various problems. When the relationship between the response organization and the media weakens, each party's motives and its trustworthiness as an information source are questioned. Response organizations that send messages late can be perceived as not being open enough. Furthermore, losing its position as a first source makes it difficult for a response organization to protect the privacy of victims and their families during a time of increased media pressure. Because the online media nowadays can deliver news faster than ever before, it is becoming more important for public organizations to not just give the facts but also to interpret the situation and explain its consequences to the public. 
Palttala, P., Boano, C., Lund, R., and Vos, M. (2012), Communication gaps in disaster management: Perceptions by experts from governmental and non-governmental organizations. Journal of Contingencies and Crisis Management. Vol.20, Issue 1, pp.1-12. DOI: 10.1111/j.1468-5973.2011.00656.x

\section{Expert manpower for media relations}

The scene of the crisis is often chaotic and rescue workers lack the capacity to deal with journalists at the site of the event. Interviews and photographs often take place in the field with officials and eye witnesses rather than with trained spokespeople in an organization's headquarters. Adequate human resources to perform communication tasks are needed not only in the command centre but also in the field. There was an evident need for the importance of communication to be acknowledged on the higher managerial level, and some respondents suggested that for crisis preparedness, communication training needs also to reach the grassroots level.

"The media want the story out immediately as it is happening and staff needs to be dedicated for this - The media want people at the crisis site, not comments from head offices. “

[Project/programme manager of a non-governmental organization with experience in humanitarian emergencies, technological/man-made disasters, disaster preparedness and mitigation, recovery, and conflict in the Middle East and Africa]

"I think one big error is not to involve a crisis communication team or person responsible for it into management level.”

[Project/programme manager in a governmental organization with experience in natural disasters, technological/man-made disasters, disaster preparedness and mitigation and crowd management in Europe]

\section{Accountability}

In media relations, the biggest challenge after a crisis is the blame game. The respondents mentioned that in the aftermath of a crisis the news media often turn to the apportioning of blame, with the authorities being accused of possible mistakes and inadequacy or of being slow to act. It is also a time for accountability and the rebuilding of trust if it has been broken. Response organizations should understand that the orientation of the media is different in the phase after a crisis, and that even when they are not implicated in the cause of the crisis they may face critical questions. For this purpose also, media relations need timely attention. According to the respondents, a precondition for preventing unnecessary collision with the media at this stage is to ensure the participation of communication experts at the management level where decisions are made. It might also then be possible to address prejudice about the media's motives. As one of the respondents stated, the media are expected to focus on negative points of view, and to an uncritical audience.

"The media could provide a very important educational service, but being business organizations, they do not really seek to provide services, but to make profit. The general public is vulnerable to propaganda, unless already informed or trained to think independently about the reasons why disasters occur.” 
Palttala, P., Boano, C., Lund, R., and Vos, M. (2012), Communication gaps in disaster management: Perceptions by experts from governmental and non-governmental organizations. Journal of

Contingencies and Crisis Management. Vol.20, Issue 1, pp.1-12. DOI: 10.1111/j.1468-5973.2011.00656.x

[Policy advisor, project/programme manager, with experience in natural disasters and educational programs in Asia]

\subsection{Communication constraints with citizens}

According to the current understanding of the field of public relations, dialogue with various stakeholders is the core of communication. This is equally the case in crisis situations. The traditional sender-oriented thinking has lost ground in the literature to a new receiver-focused approach. Monitoring the needs and expectations of people in the social environment is a central function of public relations in times of crisis. Although the importance of listening to the relevant publics has been acknowledged in the literature, the respondents nevertheless noted that in practice the receiver orientation in communication with civilians and miscellaneous groups continues, for various reasons, to remain a challenge for response organizations.

\section{The human perspective}

Response organizations often fail to meet the expectations of all the diverse public groups, and hence neglect the human perspective. This could be addressed prior to crises occurring. As in many instances in the literature, the results of the present questionnaire acknowledged that the starting point for crisis communication should be people - the directly and indirectly affected civilians and communities, and their needs. The respondents felt that they should not only be prioritized in time but also in the content and focus of the communication. Societal readiness to cope with a crisis situation can be seen as an important precondition. In part, societal readiness has to do with the resources and response capability available. It is also the ability to make informed decisions and take action in terms of relief. Moreover, the level of social capital in society matters. Communication with the public is important because it affects public perception and behaviour.

In the preparedness phase more attention could be given to an attitude of empowerment. Open communication with affected individuals and communities was stated to facilitate selfefficacy, i.e. the belief of people that they can protect themselves, and hence have control over the situation. This, combined with participation in decision-making, can have a positive impact on people's well-being.

"I believe that efficient communication with affected individuals and communities facilitates their participation in the decision-making and that has an important impact on their survival and well-being."

[Project/programme manager in a non-governmental organization with experience in humanitarian emergencies, technological/man-made disasters, disaster preparedness and mitigation, recovery and conflict in Middle East and Africa] 
Palttala, P., Boano, C., Lund, R., and Vos, M. (2012), Communication gaps in disaster management: Perceptions by experts from governmental and non-governmental organizations. Journal of Contingencies and Crisis Management. Vol.20, Issue 1, pp.1-12. DOI: 10.1111/j.1468-5973.2011.00656.x

The preparedness phase gives opportunities to address possible crises. The respondents suggested that familiarity lessens perceived uncertainty in a crisis situation, while new and so far unexperienced threats seem to be more frightening. Also, consciously taken risks may be perceived as less harmful than those out of people's own control.

"On the one hand, a risk that is taken consciously is felt to be smaller than a risk which is not controllable (e.g. smoking versus a train accident). On the other hand, the familiarity of risk matters, since new things seem more frightening and threatening (new technologies versus flooding)."

[Communication expert of a governmental organization with experience in disaster preparedness and mitigation and communication with press and public in Europe]

\section{Monitoring}

Throughout a crisis it is considered important to listen to concerns and needs of citizens. The respondents address this as a prerequisite of interaction and dialogue. However, assessment of the needs of an affected population was claimed to be time-consuming, whereas lifesaving activities require rapid action. Knowing the audience and its views calls for monitoring; this was seen to be one of the core roles of public relations. Understanding the risk perception mechanisms of people requires a thorough analysis of, for example, their background, level of knowledge and expectations. The experiences people have affect how they cope with a crisis situation. The respondents stated that in cases where the community had not been exposed to similar disasters before, the crisis response climate was thought to be more difficult due to a lack of understanding. It takes time to build a common platform and set a path for long-term recovery. Also, it is considered a challenge to explain possible risks that may not seem realistic or are difficult to fathom. In some cases also a lack of public or political interest in a topic hinders communication.

"It is difficult for a relief agency to be aware of the multiple ways in which communities perceive a crisis. The tsunami for any local inhabitant might have represented among other things: an individual's deadly threat with possible physical or psychological harm, losses within the family, changed demography in the community, changed inventory of resources and balance of power in the district, new dynamics in an existing provincial conflict, economic opportunities associated with provincial reconstruction, and large global exposure."

[Policy advisor and programme manager with experience in humanitarian emergencies, natural disasters, disaster preparedness and mitigation and]

During a crisis the course of events is not easy to predict. Nevertheless response organizations need to assess the situation quickly and accurately, as one respondent stated, avoiding overly 
Palttala, P., Boano, C., Lund, R., and Vos, M. (2012), Communication gaps in disaster management: Perceptions by experts from governmental and non-governmental organizations. Journal of

Contingencies and Crisis Management. Vol.20, Issue 1, pp.1-12. DOI: 10.1111/j.1468-5973.2011.00656.x

optimistic predictions about a problem and never dismissing peoples' fears and concerns. The stakeholder landscape, however, is not homogeneous or simple, a fact which needs to be taken into account in communication planning. The respondents stated that it is often assumed that in the first response phase a more standardised form of communication can be used, while it is agreed that the later rehabilitation and recovery phases need more complex forms of exchange. This was criticised as possibly leading, for instance, to gender insensitivity in the initial relief operations, or to neglecting people with disabilities in the immediate response to a disaster. Accurate targeting is also needed in the first stage of crisis response. The message has to address the various stakeholder levels of the emergency (individual, family, community, province, ethnic group and so on). In the initial relief operations the message is mainly targeted at a limited and very vulnerable group; later, as the primary concern shifts from the relief to the rehabilitation and then recovery phases, the target of the messages expands.

Defining stakeholders and monitoring their expectations is difficult, but this is also true of the sending of the actual messages. Groups of affected people may be spread over several locations. Extensive communication covering various means and channels is important because of people's different patterns of media consumption. In addition, the respondents warned that citizens may not recall the information given, and suggested the use of combined methods, e.g. reinforcing oral messages by written reminders. When monitoring reactions of citizens, the social media also need to be addressed.

\section{Enhancing trust}

Believable messages are credible and enhance trust (Seeger, 2006). Maintaining confidence is a challenge which can be overcome by openly explaining difficulties and what has been done in order to avoid severe consequences or additional harm. Building trust requires not just professional expertise to rescue people and mitigate harmful consequences, but also openness and empathy, explaining decisions and alternatives. The respondents stressed that crisis messages should tell people what can and cannot be done by the authorities, what people can and cannot do for themselves, and where to get more information about the crisis event.

Public authorities are often afraid to cause panic, a concern which may lead them to withhold information. However, making information available offers people the chance to make better-informed choices (Reynolds and Seeger, 2005). According to the respondents, in crisis communication, honesty, candour and openness constitute a golden section. Accurate, widely distributed and timely information is expected to reduce anxiety and strengthen people's sense of self-efficacy and encourage them to take of protective measures.

"In the crisis communication with citizens, I advice to conduct open, timely, consequent and comprehensible messages, in which also facts and figures as well as perspectives of action (what can be done), and significance (what does it mean) are attributed." 
Palttala, P., Boano, C., Lund, R., and Vos, M. (2012), Communication gaps in disaster management: Perceptions by experts from governmental and non-governmental organizations. Journal of

Contingencies and Crisis Management. Vol.20, Issue 1, pp.1-12. DOI: 10.1111/j.1468-5973.2011.00656.x

[Communication expert in a governmental organization with experience in communication with press and the public in Europe]

"People must get facts of what is happening and what they can do to protect themselves and others or not to cause any greater harm to the situation. Clear, short facts and instructions (this is happening, do this, don't do that). Ignorance easily causes panic; therefore it benefits the authorities if people are well-informed."

[Communication expert in a governmental organization with experience in natural disasters and crime in Europe]

It is advised to mix potential alarming elements of information with reassuring elements. Clarity is crucial in the construction of crisis messages, as inadequate communication was said to lead to confusion and public mistrust. After a crisis, people expect explanations of what happened as well as answers to what is being done to minimize similar risks in the future. Therefore, also in worst-case scenarios, where this is possible, authorities should explain what is currently known or not known. What should be avoided in crisis messages is creating unrealistic expectations.

"In their communication, public authorities should avoid overly optimistic predictions about a problem and never dismissing peoples' fears and concerns.”

[Communication expert and academic researcher of an academic institution/research centre/policy institution with experience in humanitarian emergencies, natural disasters, technological/man-made disasters, terrorism and disaster preparedness and mitigation in Europe]

In this way, trust is a result of actions and communication throughout all the crisis phases. The respondents stressed that trust also needs attention when measures are taken in the reconstruction phase and people question whether their point of view is being taken into account. In this phase media attention may be relatively low but communication is nevertheless important for public perception.

\section{Conclusions}

This study aims at identifying gaps which crisis managers and communication experts have encountered in crisis communication in practice. The questionnaire results showed that communication is not yet firmly based in disaster management practice. Although crisis communication plans, lists of best practices and other types of guidelines exist, communication as an integral part of decision-making needs to be developed further. The complexity of presentday crises calls for communication strategies which match the expectations of different stakeholder groups in the various types and phases of a crisis. This is in line with the CERC model by Reynolds and Seeger (2005), presented earlier, which suggests that a single phase often 
Palttala, P., Boano, C., Lund, R., and Vos, M. (2012), Communication gaps in disaster management: Perceptions by experts from governmental and non-governmental organizations. Journal of Contingencies and Crisis Management. Vol.20, Issue 1, pp.1-12. DOI: 10.1111/j.1468-5973.2011.00656.x

requires multiple methods of communication due to diverse and segmented audiences. The CERC model, however, could benefit from the more specific stakeholder perspectives presented in the present paper and the bottlenecks found which add to the phase-specific communication tasks defined earlier by Reynolds and Seeger. An overview is presented in table 2 . The results are tentatively connected to the different crisis phases.

Table 2. Overview of problems of communication in crisis management practice mentioned by the respondents

\begin{tabular}{|l|l|l|l|}
\hline Crisis phases: & Response network & News media & Citizens \\
\hline Before & $\begin{array}{l}\text { The role of } \\
\text { communication should be } \\
\text { clarified }\end{array}$ & $\begin{array}{l}\text { Relationships and } \\
\text { expectations need } \\
\text { attention }\end{array}$ & $\begin{array}{l}\text { Preparedness plans need } \\
\text { to start from the human } \\
\text { perspective }\end{array}$ \\
\hline During & $\begin{array}{l}\text { The information flow } \\
\text { within the network needs } \\
\text { attention }\end{array}$ & $\begin{array}{l}\text { Expert manpower for } \\
\text { media relations round the } \\
\text { clock is often lacking }\end{array}$ & $\begin{array}{l}\text { The importance of } \\
\text { continuous monitoring is } \\
\text { underestimated }\end{array}$ \\
\hline After & $\begin{array}{l}\text { Evaluation and learning } \\
\text { should be strengthened }\end{array}$ & $\begin{array}{l}\text { Accountability requires a } \\
\text { different focus }\end{array}$ & $\begin{array}{l}\text { The paying of attention to } \\
\text { enhancing trust needs to } \\
\text { be continued }\end{array}$ \\
\hline
\end{tabular}

The main gaps in communication were discussed in the context of cooperation across the response network, media relations, and communication with citizens. Coordination among response organizations presents a challenge, as todays' crises are complex and responses to them involve multiple actors. Every organization works in its own way and therefore more uniform decision-making and coordination of communication are needed. The functions and importance of communication should be clarified. Inadequate knowledge of the roles, tasks and working methods of other actors hampers the ability to cooperate. Standard operating procedures, lessons learned and cooperative training add to crisis preparedness.

Media relations were considered as important and demanding. Nowadays it is considered necessary to protect responders and victims from media pressure, and therefore public authorities need to accentuate their position as the main sources of information. The partner role of the media is recognised but could be capitalized on better. More media training was also suggested.

Two-way communication with citizen groups needs a detailed, contextualized approach. The large variety of such groups calls for multiple communication strategies. However, defining groups, their backgrounds, information needs and perception of risks is not yet a core competence in practice. Crisis communication requires attentive targeting, which means that messages addressing various stakeholder levels should be based on careful monitoring of the communication needs of the various publics involved. Strengthening the self-efficacy of publics 
Palttala, P., Boano, C., Lund, R., and Vos, M. (2012), Communication gaps in disaster management: Perceptions by experts from governmental and non-governmental organizations. Journal of

Contingencies and Crisis Management. Vol.20, Issue 1, pp.1-12. DOI: 10.1111/j.1468-5973.2011.00656.x

should also be a communication goal of response organizations, since the threat to be handled is lessened if civilians themselves are able to act. Perceptions of credibility and trust towards public authorities also influences risk perception. For the building of trust it is not just expertise in implementing rescue activities and mitigating harmful consequences that are required, but also openness and empathy when explaining decisions and alternatives.

It is for future crisis communication research to look into the areas mentioned. Such efforts could be conducted from the perspective of strengthening the preparedness of the response network, clarifying the quality criteria for communication, and addressing hindrances or dilemmas for further consideration and dialogue. By making the bottlenecks more visible and connecting them in a generalized form to the different crisis phases, it will be easier for organizations to see potential underachievement, and hence improve action.

To support evaluation and learning about crisis communication an audit instrument could be developed that follows the framework of, on the one hand, the different crisis phases and, on the other hand, the requirements of stakeholder groups. A variety of communication constraints was mentioned that seems to correspond with insights in the literature, but there were also mentions of problems felt nowadays in practice, like the need to further clarify the role and tasks of communication supporting crisis management. The audit instrument should specify communication tasks and address the constraints found here. The results emphasise the role of joint communication strategies in the response network, the importance of facilities, training and having enough expert manpower, and the importance of engaging in advanced monitoring activities throughout a crisis.

It should be also noted that the situation differs across countries; for example, in some countries public crisis communication is better resourced than in others. For this reason to obtain a reliable and comprehensive picture that would reveal cross-country differences in crisis communication preparedness would need more thorough quantitative research. More careful comparison between governmental and non-governmental organizations, and attention to the diverse nature of crises might provide more detailed information about the gaps in communication in different crisis situations.

\section{Acknowledgements}

The research project leading to these results has received funding from the European Community's Seventh Framework Programme (FP7/2007-2013) under grant agreement $n^{\circ}$ 217889. 
Palttala, P., Boano, C., Lund, R., and Vos, M. (2012), Communication gaps in disaster management:

Perceptions by experts from governmental and non-governmental organizations. Journal of

Contingencies and Crisis Management. Vol.20, Issue 1, pp.1-12. DOI: 10.1111/j.1468-5973.2011.00656.x

\section{References}

Coombs, W.T. (1995), 'Choosing the Right Words: The Development of Guidelines for the Selection of the "Appropriate" Crisis-response Strategies', Management Communication Quarterly, Volume 4, pp. 447-476.

Coombs, W.T. (2004), 'Impact of Past Crises on Current Crisis Communication: Insights from Situational Crisis Communication Theory', Journal of Business Communication, Volume 41, Number 3, pp. 265-289.

Falkheimer, J. and Heide, M. (2006), 'Multicultural Crisis Communication: Towards a Social Constructionist Perspective', Journal of Contingencies and Crisis Management, Volume 14, Number 4, pp. 180-189.

Fassin, Y. (2008), Imperfections and Shortcomings of the Stakeholder Model's Graphical Representation, Journal of Business Ethics, Volume 80, pp. 879-888.

Freeman, R. (1984), Strategic Management: A Stakeholder Approach, Ballinger, Boston.

Kersten, A. (2005), 'Crisis as Usual: Organizational Dysfunction and Public Relations', Public Relations Review, Volume 31, Number 4, pp. 544-549.

Key, S. (1999), Toward a New Theory of the Firm: A Critique of Stakeholder “Theory”, Management Decision, Volume 37, Number 4, pp. 317-328.

Luoma-aho, V. \& Vos, M. (2010), Towards a more dynamic stakeholder model: The role of issue arenas for corporate reputation. Corporate Communication, an International Journal, Vol. 15, No. 3, pp. 315-331.

Lutz, L. and Lindell, M. (2008), Incident Command System as a Response Model Within Emergency Operation Centers during Hurricane Rita. Journal of Contingencies and Crisis Management. Volume 16, Issue 3, pp. 122-134.

Moe, T. L. and Pathranarakul, P. (2006), 'An Integrated Approach to Natural Disaster Management. Public Project Management and Its Critical Success Factors', Disaster Prevention and Management, Volume 15, Number 3, pp. 396-413.

Nohrstedt, S.A. and Admassu, T. (1993), Communication and Crisis: An Inventory of Current Research. National Board of Psychological Defence, Stockholm.

Ödlund, A. (2010), Pulling the Same Way? A Multi-Perspectivist Study of Crisis Cooperation in Government. Journal of Contingencies and Crisis Management. Volume 18, Issue 2, pp. 96-107.

Palm, J. and Ramsell, E. (2007), Developing Local Emergency Management by Co-Ordination Between Municipalities in Policy Networks: Experiences from Sweden. Journal of Contingencies and Crisis Management, Volume 15, Issue 4, pp. 173-182.

Pauchant, T.C. and Mitroff, I. I. (1992), Transforming the Crisis-prone Organizations. Jossey-Bass Publishers, San Francisco, CA. 
Palttala, P., Boano, C., Lund, R., and Vos, M. (2012), Communication gaps in disaster management:

Perceptions by experts from governmental and non-governmental organizations. Journal of

Contingencies and Crisis Management. Vol.20, Issue 1, pp.1-12. DOI: 10.1111/j.1468-5973.2011.00656.x

Reynolds, B. and Seeger, M.W. (2005), 'Crisis and Risk Communication as an Integrative Model', Journal of Health Communication, Volume 10, pp. 43-55.

Seeger, M. W. (2006), 'Best Practices in Crisis Communication: An Expert Panel Process', Journal of Applied Communication Research, Volume 34, Number 3, pp. 232-244.

Sellnow, T. L. (1993), 'Scientific Argument in Organizational Crisis Communication: The Case of Exxon', Argumentation and Advocacy, Volume 30, pp. 28-42.

Ulmer, R. R, Seeger, M. W. and Sellnow, T. L. (2007), Effective Crisis Communication. Moving from Crisis to Opportunity. Sage Publications, Thousand Oaks.

Visuri, P. (2003), 'Miten kriisinhallintaa pitäisi kehittää?', in T. Forsberg, C. Pursiainen, R. Lintonen, and P. Visuri (Eds), Suomi ja kriisit; vaaranvuosista terrori-iskuihin, Gaudeamus, Helsinki, pp. 315-334.

Vos, M. and Schoemaker, H. (2006), Monitoring Public Perception of Organizations, Boom Onderwijs, Amsterdam.

Weick, K. E. and Sutcliffe, K. M. (2007), Managing the Unexpected (2nd edition), Jossey-Bass Publishers, San Francisco, CA.

Wendling, C. (2010), Explaining the Emergence of Different European Union Crisis and Emergency Management Structures. Journal of Contingencies and Crisis Management, Volume 18, Issue 2, pp. 74-82. 